\title{
Chlorination of Carbon Nanotubes Obtained on the Different Metal Catalysts
}

\author{
Iwona Pełech, ${ }^{1}$ Robert Pełech, ${ }^{2}$ Urszula Narkiewicz, ${ }^{1}$ Dariusz Moszyński, \\ Anna Jędrzejewska, ${ }^{1}$ and Bartłomiej Witkowski ${ }^{3}$ \\ ${ }^{1}$ Institute of Chemical and Environmental Engineering, West Pomeranian University of Technology in Szczecin, \\ Pułaskiego 10, 70-310 Szczecin, Poland \\ ${ }^{2}$ Institute of Organic Chemical Technology, West Pomeranian University of Technology in Szczecin, Pułaskiego 10, \\ 70-310 Szczecin, Poland \\ ${ }^{3}$ Institute of Physics, Polish Academy of Sciences, Al. Lotnikow 32/46, 02-668 Warsaw, Poland
}

Correspondence should be addressed to Iwona Pełech; ipelech@zut.edu.pl

Received 10 October 2013; Accepted 29 November 2013

Academic Editor: Chunyi Zhi

Copyright (C) 2013 Iwona Pełech et al. This is an open access article distributed under the Creative Commons Attribution License, which permits unrestricted use, distribution, and reproduction in any medium, provided the original work is properly cited.

In this paper, a chlorination method is proposed for simultaneous purification and functionalization of carbon nanotubes, thus increasing their ability to use. Carbon nanotubes were obtained by CVD method through ethylene decomposition on the nanocrystalline iron or cobalt or bimetallic iron-cobalt catalysts. The effects of temperature $\left(50,250\right.$, and $\left.450^{\circ} \mathrm{C}\right)$ in the case of carbon nanotubes obtained on the $\mathrm{Fe}$-Co catalyst and type of catalyst $(\mathrm{Fe}, \mathrm{Co}, \mathrm{Fe} / \mathrm{Co}$ ) on the effectiveness of the treatment and functionalization were tested. The phase composition of the samples was determined using the X-ray diffraction method. The quantitative analysis of metal impurity content was validated by means of the thermogravimetric analysis. Using X-ray Photoelectron Spectroscopy (XPS), Energy Dispersive Spectroscopy (EDS) analysis, and also Mohr titration method, the presence of chlorine species on the surface of chlorinated samples was confirmed.

\section{Introduction}

Carbon nanotubes (CNTs), since their discovery in 1991, constantly incite an immense interest owing to their special physical and chemical properties. Due to unique mechanical, thermal, and electrical properties, these materials are not only an ideal candidate for many applications but also a very interesting material from a scientific point of view. Concerning industrial applications carbon nanotubes can be used, for example, as electron emitters, filtration membranes, drug carriers, energy containers, or catalyst supports [1-6]. A particular interest is connected with the application of carbon nanotubes as fillers for polymers. The presence of carbon nanotubes as an additive to a polymer can improve such properties of the composite such as tensile strength [7], tensile modulus [8], toughness [9], glass transition temperature [10], thermal conductivity [11], resistance to solvents [12], optical properties [13], and electrical conductivity [14].
The main bottleneck in the application of carbon nanotubes as fillers for polymers is their insufficient dispersion in a polymer matrix, because CNTs have a tendency to agglomerate due to the Van der Waals forces. Recently there are several methods improving the dispersion of carbon nanotubes in a polymer matrix. One of the very promising methods preventing an aggregation of nanotubes and facilitating a good dispersion in a polymer matrix is their chemical functionalization, involving changes of the surface of nanotubes through an addition of various functional groups.

The most popular method of carbon nanotubes functionalization is their oxidation using oxygen $[15,16]$ or $\mathrm{KMnO}_{4}$, $\mathrm{H}_{2} \mathrm{O}_{2}$, or $\mathrm{O}_{3}[17,18]$. To oxidize carbon nanotubes, it is also possible to apply strong acids in liquid environment, as, for example, $\mathrm{HNO}_{3}, \mathrm{HClO}_{4}, \mathrm{H}_{2} \mathrm{SO}_{4}+\mathrm{K}_{2} \mathrm{Cr}_{2} \mathrm{O}_{7}$, or $\mathrm{H}_{2} \mathrm{SO}_{4}+$ $\mathrm{KMnO}_{4}$ [19-21]. Such reactions can cause an addition of many functional groups, as, for example, of carboxyl, alcohols, ketones, or esters $(-\mathrm{COOH},-\mathrm{OH},>\mathrm{C}=\mathrm{O}$, or $-\mathrm{COO}-$, resp.) to the external walls of tubes. It should be highlighted 
that hydroxyl or carboxyl groups are often used as precursors for further reactions of silanisation [22], esterification [23], or alkylation and arylation [24].

Functionalization of carbon nanotubes can be also conducted using other ways as, for example, fluorination, chlorination, or attachment of compounds with longer chains. Fluorination of nanotubes involves the attachment of fluorine to the carbon structure which improves the solubility of carbon nanotubes in polar solvents, for example, alcohols, resulting in the creation of hydrogen bond between the molecule of attached fluorine and the molecule of alcohol [25]. To chemically attach fluorine to the tubes, various sources of fluorine can be applied, as atomic fluorine, gaseous fluorine and inorganic fluorides, $\mathrm{as}_{\mathrm{BrF}_{3}}$ or $\mathrm{XeF}_{2}[25,26]$. The attachment of the fluorine molecule enables in further reactions (similarly as in the case of other functional groups) the replacement of fluorine with more complicated substituents. The covalent bond of fluorine can be replaced by, for example, alkyl group through an alkylation reaction [26]. The reactants in this reaction can be alkylolite or reactants of the Grignard reaction, for example, $\mathrm{RMgX}$ (where $\mathrm{R}$-alkyl group, $\mathrm{X}-\mathrm{Cl}$, or $\mathrm{Br}, \mathrm{I})$.

An alternative method of carbon nanotubes functionalization is their chlorination. Chlorine applied in the functionalization of carbon nanotubes can originate from liquid precursors as thionyl chloride, chloroform, trichloromethane, tetrachloroethylene [27], or hydrochloric acid [28] or solid as dichlorocarbene [29] or gaseous precursors as $\mathrm{Cl}_{2}$ [30]. In the result of the chlorination reaction the following groups can be attached to the external walls of carbon nanotubes: $\mathrm{CCl}_{2},-\mathrm{CCl}$, or $-\mathrm{COCl}[28]$.

In this paper, modification of carbon nanotubes obtained on the iron, cobalt, and bimetallic iron/cobalt catalyst using chlorination method in the gas phase is presented. Chlorination reaction is very interesting and promising because it may be an intermediate stage that allows for the subsequent fixation of more complex functional groups. The effect of the temperature on the modification of carbon nanotubes obtained on the iron-cobalt catalyst and the influence of chlorination treatment on the removal of iron, cobalt, and iron-cobalt particles as well as on the attachment of functional groups were investigated. The amount of chlorine species was confirmed using Energy Dispersive Spectroscopy (EDS) analysis and X-ray photoelectron spectroscopy (XPS). Removal degree of metal particles was determined on the basis of thermogravimetric analysis.

\section{Experimental}

Nanocrystalline iron, cobalt, and iron/cobalt were obtained from cobalt (II) or iron (III) nitrates together with a small amount of calcium and aluminum nitrates. The salts were dissolved in water and $20 \% \mathrm{NH}_{4} \mathrm{OH}$ was added as a precipitating agent continuously, to obtain a $\mathrm{pH}$ of 8 . Metal hydroxides were precipitated from the solution and the deposit was washed with water, filtered, and dried at $75^{\circ} \mathrm{C}$. The next step was calcination at $500^{\circ} \mathrm{C}$ for $1 \mathrm{~h}$ to obtain the precursors of nanocrystalline metals-cobalt and iron oxides with a small amount of structural promoters $-\mathrm{CaO}$ and $\mathrm{Al}_{2} \mathrm{O}_{3}$. In the last stage of preparation, the precursors of nanocrystalline metals were reduced under hydrogen atmosphere polythermally at the temperature rising from $20^{\circ} \mathrm{C}$ to $500^{\circ} \mathrm{C}$ (for cobalt and iron/cobalt oxides) and from $20^{\circ} \mathrm{C}$ to $600^{\circ} \mathrm{C}$ for iron oxide. For all catalysts, reduction processes were conducted until the mass was stable for at least $90 \mathrm{~min}$. The details of the catalysts preparation are presented in [31].

Multiwalled carbon nanotubes (MWCNTs) were obtained by decomposition of ethylene on the nanocrystalline iron, cobalt, and bimetallic iron-cobalt catalyst at $700^{\circ} \mathrm{C}$ in the high temperature furnace (Carbolite, STF 16/180). The details of carbon nanotubes preparation are presented in [32].

The chlorination processes were performed in the gas phase for 2 hours. For this purpose, the sample was placed in the furnace and chlorine gas was supplied. Temperature of the process was kept at $50^{\circ} \mathrm{C}, 250^{\circ} \mathrm{C}$, or $450^{\circ} \mathrm{C}$. After two hours the supply of chlorine was cut off and the sample was cooled to the room temperature under vacuum. In the next stage, the sample was washed with acetone and distilled water several times and dried under vacuum at $120^{\circ} \mathrm{C}$.

The raw samples were named as $\mathrm{Fe}$ or $\mathrm{Co}$ or FeCo and the samples after chlorination as $\mathrm{FeCo} 50 \mathrm{Cl}, \mathrm{FeCo} 250 \mathrm{Cl}$, $\mathrm{FeCo} 450 \mathrm{Cl}$, or $\mathrm{Fe} 450 \mathrm{Cl}, \mathrm{Co} 450 \mathrm{Cl}$. The number indicates chlorination temperature. For example, $\mathrm{FeCo} 50 \mathrm{Cl}$ is carbon material obtained using Fe-Co catalyst and submitted to chlorination at $50^{\circ} \mathrm{C}$.

The phase composition of the sample before and after chlorination was determined using the X-ray diffraction method (X'Pert PRO Philips diffractometer), a $\mathrm{CuK}_{\alpha}$ radiation. The morphology of carbon nanomaterials was studied using Transmission Electron Microscopy (HRTEM-FEI Tecnai F20). The amount of the catalyst in the samples after chlorination process was determined based on thermogravimetric analysis, which was performed on DTA-Q600 SDT TA Instruments apparatus with the heating rate of $10^{\circ} \mathrm{C} / \mathrm{min}$ from room temperature to $900^{\circ} \mathrm{C}$ in air. The $\mathrm{X}$-ray photoelectron spectra were obtained using $\mathrm{Mg} \mathrm{K}_{\alpha}(h \nu=1253.6 \mathrm{eV})$ radiation with an SES 2002 spectrometer operating at constant transmission energy $(\mathrm{EP}=50 \mathrm{eV})$. Chemical composition analysis was performed on the Scanning Electron Microscope Hitachi SU-70 equipped with Thermo EDS system using $15 \mathrm{kV}$ of electron beam accelerating voltage.

\section{Results and Discussion}

The morphology of the carbon material obtained on the bimetallic iron-cobalt catalyst using ethylene as a carbon source at $700^{\circ} \mathrm{C}$ was studied using transmission electron microscopy and TEM images are presented in Figures 1(a) and $1(b)$. It was found that the sample was mainly composed of multi walled carbon nanotubes with diameters in the range from 20 to $40 \mathrm{~nm}$. CNTs were entangled due to the existence of carbon penta- and heptagons rings [33]. Lack of catalyst crystallites on the ends of carbon nanotubes can suggest that their growth could take place according to the root mechanism presented in [34]. TEM images of the carbon materials prepared on the nanocrystalline iron 


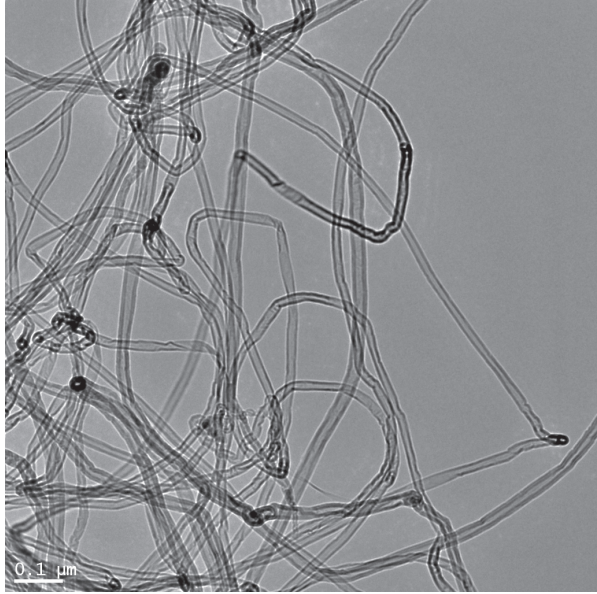

(a)

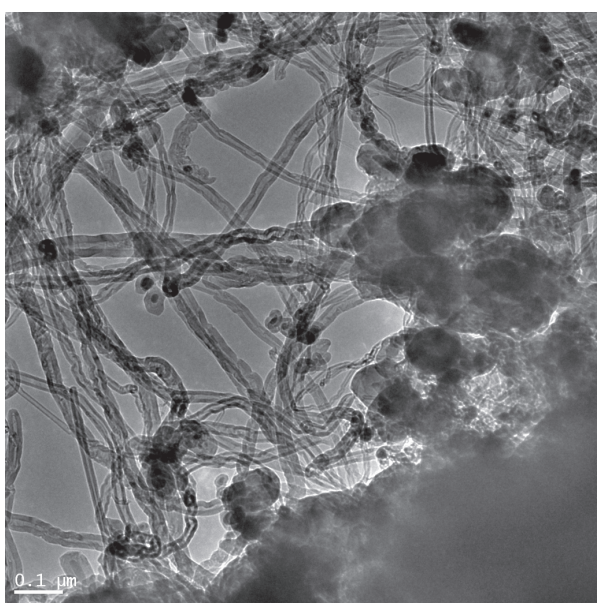

(c)

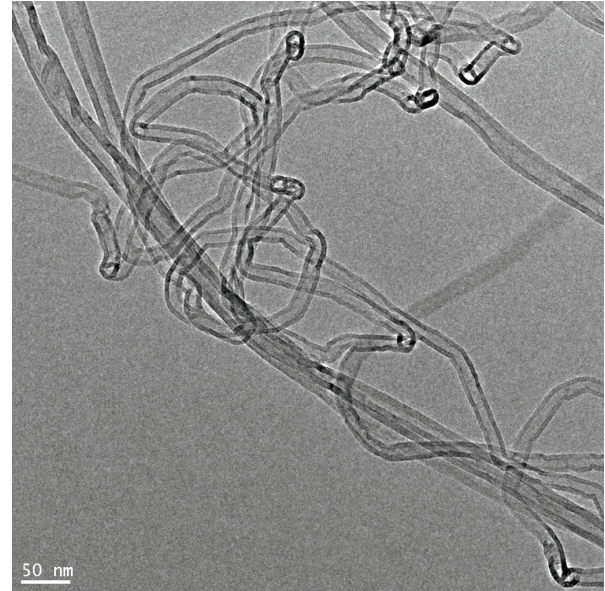

(b)

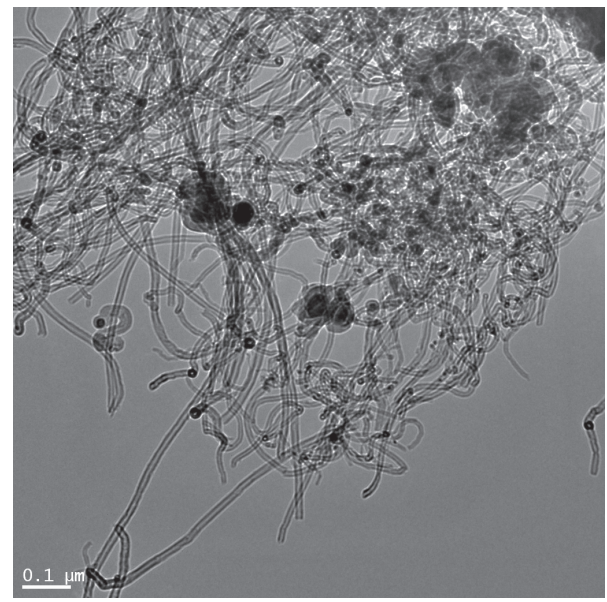

(d)

FIGURE 1: TEM images of the carbon material obtained on the bimetallic Fe-Co ((a), (b)) iron (c), and cobalt (d) catalysts.

and cobalt catalysts are presented in Figures $1(\mathrm{c})$ and $1(\mathrm{~d})$, respectively. Carbon filamentous structures were observed in both cases. It was also clearly visible that the diameters of the filaments obtained on the cobalt catalyst were smaller than those obtained on the iron catalyst. Additionally, the bigger particles encapsulated in carbon were observed, which were not active in the carbon nanotubes formation.

Carbon material obtained on the bimetallic iron-cobalt catalyst was submitted to chlorination in the gas phase at $50^{\circ} \mathrm{C}, 250^{\circ} \mathrm{C}$, or $450^{\circ} \mathrm{C}$. In order to compare the effectiveness of chlorination methods towards the removal of catalyst particles and introduction of functional groups on the carbon nanotubes surface, carbon materials obtained on the iron and cobalt catalyst were also tested.

The preliminary analysis of the samples was done using $\mathrm{X}$-ray diffraction method. The XRD spectra of the raw carbon materials synthesized on the iron/cobalt catalysts $(\mathrm{FeCo})$ and carbon materials after chlorination at $50^{\circ} \mathrm{C}$ and $450^{\circ} \mathrm{C}$ (samples $\mathrm{FeCo} 50 \mathrm{Cl}$ and $\mathrm{FeCo} 450 \mathrm{Cl}$ ) are presented in Figure 2. On the basis of the XRD analysis, it was found that the raw carbon sample consisted of graphite and Fe-Co phase.
For the samples after chlorination at different temperatures, the phase composition was almost the same. Simultaneously none of ferric chloride or cobalt chloride was detected. Significant changes were observed as for the intensity of the $\mathrm{Fe}-\mathrm{Co}$ peaks. For the samples after chlorination at $50^{\circ} \mathrm{C}$ and at $250^{\circ} \mathrm{C}$ (not show here), the peaks from $\mathrm{Fe}-\mathrm{Co}$ phase were decreased and at $450^{\circ} \mathrm{C}$ almost completely disappeared.

The efficiency of the chlorination method conducted at $450^{\circ} \mathrm{C}$ to the removal of iron and cobalt particles was also examined and X-ray diffraction spectra of the raw and chlorinated samples are presented in Figure 2. In the case of iron sample after synthesis, besides peaks characteristic for the graphite phase, peaks corresponding to iron carbide in the form of cementite were detected. After chlorination, these peaks were not noticed but it cannot be excluded that in the samples small amounts of $\mathrm{Fe}_{3} \mathrm{C}$ could be present. For the sample obtained on the cobalt catalyst, similar like in the case of iron or iron/cobalt material after synthesis, graphite peaks and additionally small intensity peaks corresponding to cobalt phase were present. Probably in the sample some amount of cobalt oxide also existed. 


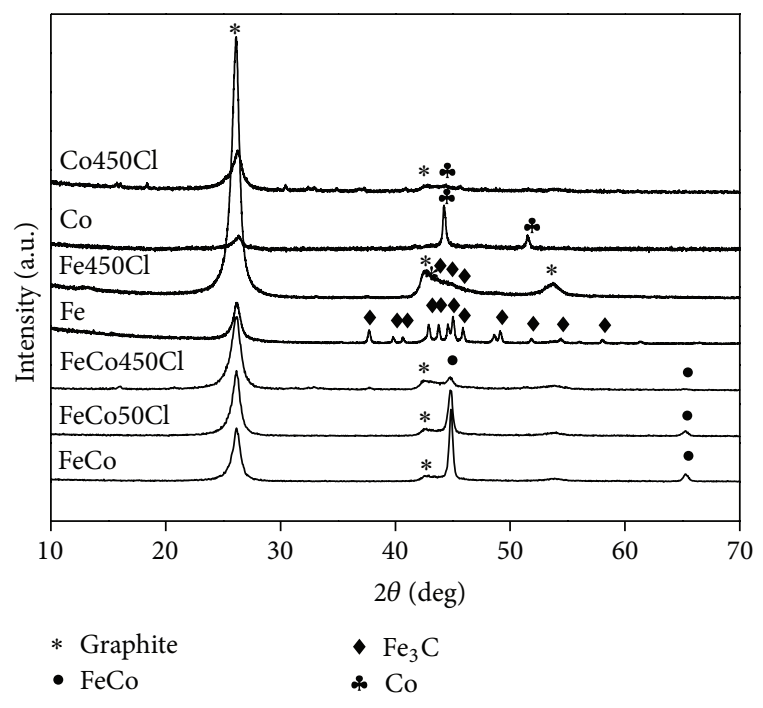

FIGURE 2: XRD spectra of the raw sample (1) and the samples after chlorination at $50^{\circ} \mathrm{C} \mathrm{(2)} \mathrm{and} 450^{\circ} \mathrm{C}(3)$.

EDS results presented in Table 1 confirmed that the amount of iron continuously decreased from $2 \%$ in the raw sample $(\mathrm{FeCo})$ to $0.3 \%$ in the sample chlorinated at $450^{\circ} \mathrm{C}(\mathrm{FeCo} 450 \mathrm{Cl})$. At moderate temperatures, the values of iron were $1.5 \%$ and $1.4 \%$ for the sample chlorinated at $50^{\circ} \mathrm{C}(\mathrm{FeCo} 50 \mathrm{Cl})$ and $250^{\circ} \mathrm{C}(\mathrm{FeCo} 250 \mathrm{Cl})$, respectively. The amount of cobalt particles in the raw sample (FeCo) was about $1.4 \%$ and did not change in the sample after chlorination at $50^{\circ} \mathrm{C}(\mathrm{FeCo} 50 \mathrm{Cl})$. At $250^{\circ} \mathrm{C}(\mathrm{FeCo} 250 \mathrm{Cl})$, the amount of cobalt decreased and equalled about $0.7 \%$ and for the sample chlorinated at $450^{\circ} \mathrm{C}$ about $0.9 \%(\mathrm{FeCo} 450 \mathrm{Cl})$.

The composition of the samples was also studied by means of XPS analysis. The results of the elemental quantitative analysis of the surface composition are presented in Table 2. In contrast to the EDS results only for samples $\mathrm{FeCo} 50 \mathrm{Cl}$ and $\mathrm{FeCo} 250 \mathrm{Cl}$ a small amount of iron was detected by XPS analysis. However, it must be kept in mind that XPS information depth reaches only several tens of nanometers from the surface while EDS technique gives the composition for a depth of several $\mu \mathrm{m}$. Presumably the iron and cobalt particles detected by EDS analysis are covered by a carbon deposit which effectively screens XPS signal of these elements from detection. In the samples treated at $50^{\circ} \mathrm{C}$ and $250^{\circ} \mathrm{C}$, the carbon deposit is supposedly thinner and small quantities of iron can be observed by XPS analysis.

In order to determine the exact amount of metal particles which remained in the samples after the chlorination process, a thermogravimetric analysis was performed. On the basis of thermogravimetric curves (shown in the Figure 3), the percentage content of catalyst, in the samples was calculated and the values are presented in Table 3. For the materials obtained on the iron/cobalt catalyst, it was clearly observed that the increase of chlorination temperature resulted in reducing the catalyst amount in the sample. After chlorination at $50^{\circ} \mathrm{C}$, the amount of metal particles equaled about $6.5 \%$. At $250^{\circ} \mathrm{C}$, the amount of catalyst particles decrease to $3.5 \%$ and at $450^{\circ} \mathrm{C}$
TABLE 1: Surface composition of the samples after chlorination calculated upon EDS data.

\begin{tabular}{lccccc}
\hline Sample & C K-line & O K-line & $\begin{array}{c}\text { Cl K-line } \\
\text { \%at. }\end{array}$ & Fe K-line & Co K-line \\
\hline FeCo & 92.8 & 3.1 & - & 2.0 & 1.4 \\
FeCo50Cl & 91.6 & 4.7 & 0.5 & 1.5 & 1.3 \\
FeCo250Cl & 92.3 & 4.0 & 1.4 & 1.4 & 0.7 \\
FeCo $450 \mathrm{Cl}$ & 90.6 & 5.5 & 2.3 & 0.3 & 0.9 \\
\hline
\end{tabular}

TABLE 2: Surface composition of the samples after chlorination calculated upon XPS data.

\begin{tabular}{lccccc}
\hline Sample & $\mathrm{C}$ & $\mathrm{O}$ & $\begin{array}{c}\mathrm{Cl} \\
\text { \%at. }\end{array}$ & $\mathrm{Fe}$ & $\mathrm{Co}$ \\
\hline $\mathrm{FeCo}$ & 97.8 & 2.2 & - & - & - \\
$\mathrm{FeCo} 50 \mathrm{Cl}$ & 94.2 & 3.4 & 1.3 & 1.1 & - \\
$\mathrm{FeCo} 250 \mathrm{Cl}$ & 94.4 & 3.8 & 1.0 & 0.8 & - \\
$\mathrm{FeCo} 450 \mathrm{Cl}$ & 97.8 & - & 2.2 & - & - \\
$\mathrm{Fe} 450 \mathrm{Cl}$ & 94.3 & 4.8 & 0.8 & - & - \\
$\mathrm{Co} 450 \mathrm{Cl}$ & 92.1 & 4.5 & 1.4 & - & - \\
\hline
\end{tabular}

TABLE 3: The amount of catalyst particles after chlorination calculated on the basis of thermogravimetric curves.

\begin{tabular}{lccccc}
\hline Sample & FeCo50Cl & FeCo250Cl & FeCo450Cl & Fe450Cl & Co450Cl \\
\hline Ash (\%) & 6.5 & 3.5 & 2.9 & 0.2 & 8.1 \\
\hline
\end{tabular}

further decrease of the catalyst amount was observed. In this sample, only $2.9 \%$ of catalyst particles was noticed. The best results were achieved for the iron material chlorinated at $450^{\circ} \mathrm{C}$. Only about $0.2 \%$ of metal particles remained in the sample. The most difficult to remove was cobalt catalyst and about $8.1 \%$ of these particles was still present in the sample after chlorination process.

TG curves clearly show that the chlorinated material obtained on the iron catalyst burned at higher temperature while the chlorinated samples prepared on the cobalt and iron/cobalt catalyst burned at lower temperature in comparison with the raw samples. It is known [8] that organic functional groups on multiwalled carbon nanotubes are thermally unstable; that is, most of them are decomposed before the onset of MWNTs weight loss. Fan et al. [35] explained burning of the sample at lower temperatures by the formation of oxygenated groups on the surface of MWCNTs during purification procedure, which are more reactive towards oxidation. Similar explanation is presented by Osorio et al. [36] and Murugesan et al. [37]. The same behavior was observed by Shen et al. [38] during thermogravimetric analysis of aminofunctionalized multiwalled carbon nanotubes. In our case, attachment of the functional groups can give similar effect but only in the case of the carbon nanotubes obtained on the cobalt and iron/cobalt catalyst. In our opinion, higher thermal stability of the carbon nanotubes prepared on the iron catalyst may be due to the presence of very small quantities of metal particles in the carbon material after chlorination process (see Table 3). According to [27] metal 


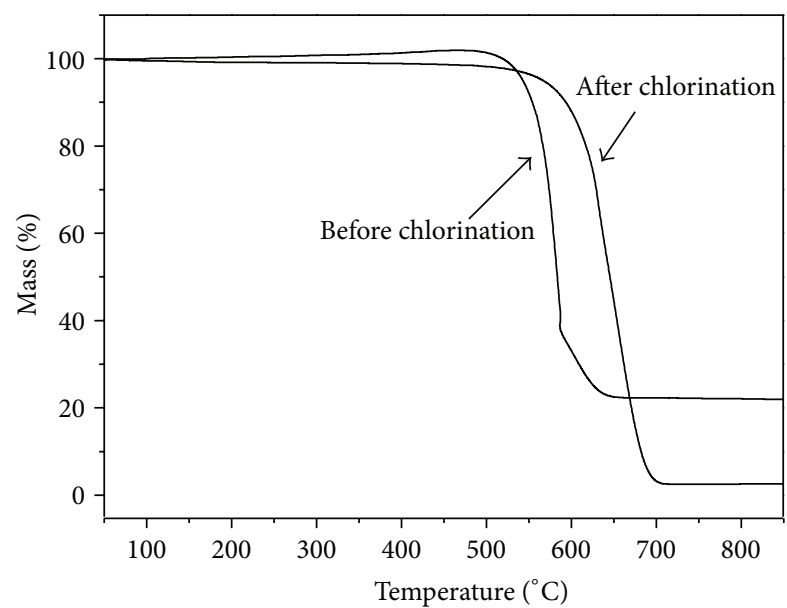

(a)

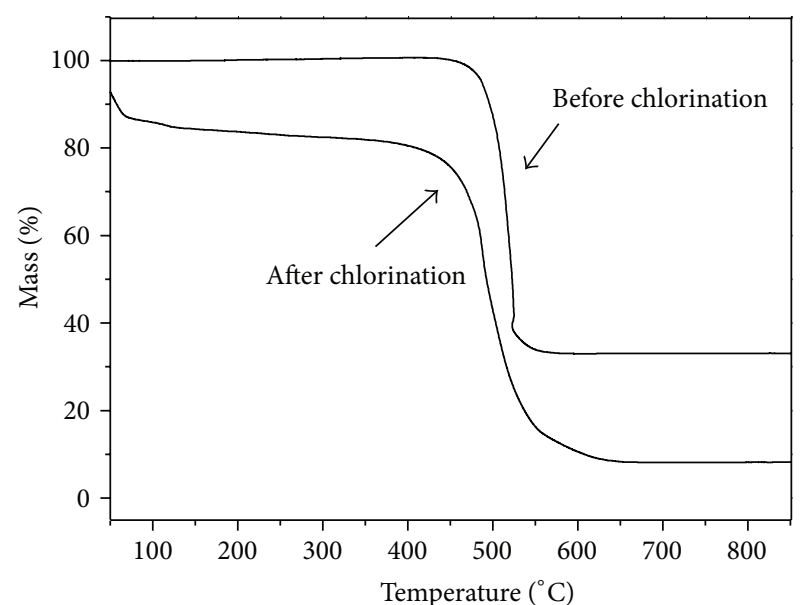

(b)

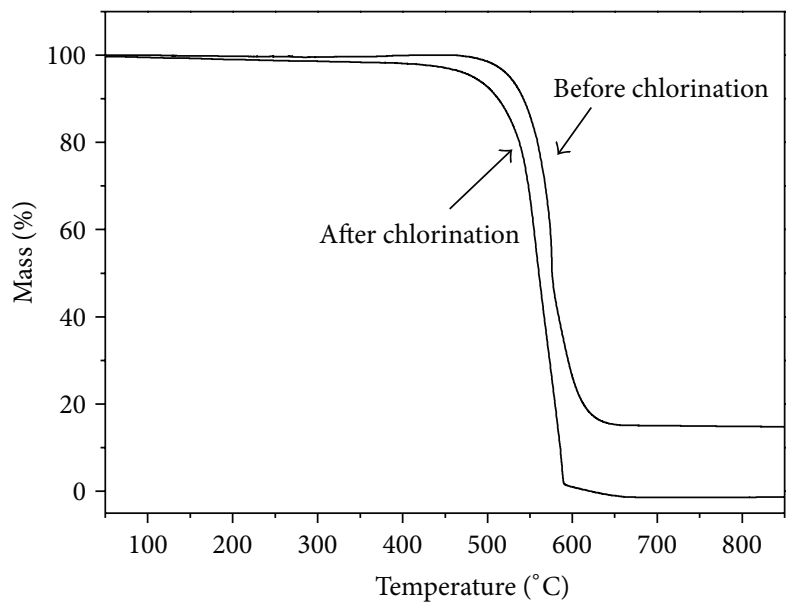

(c)

FIGURE 3: TGA curves of the raw carbon materials obtained on the iron (a), cobalt (b), and iron/cobalt (c) catalysts and the same materials after chlorination processes.

particles embedded in the raw sample act as oxidation sites and initiate the oxidation reaction. In the same work, it was also reported that the metal impurity would lower the decomposition temperature and increase the decomposition rate. That is why the purified sample is thermally more stable towards oxidative destruction than the raw one.

The presence of chlorine in the obtained samples (Fe450Cl, Co450Cl, FeCo450Cl) has been confirmed using the Mohr titration method. The results are shown in Table 4. A significant increase of the content of active chlorine can be noted in the samples after the chlorination process compared to unmodified samples. The chlorine content in the samples after the modification was the same for all the studied samples. Slightly higher value was observed only for the sample obtained on the bimetallic catalysts (FeCo450Cl).

The presence of the chlorine species in carbon material obtained using iron, cobalt, and iron-cobalt catalysts was also confirmed by EDS and XPS analysis and the results of the quantitative analysis of the composition are presented in Tables 1 and 2, respectively.
TABLE 4: Chlorine content in the samples analysed using Mohr titration method.

\begin{tabular}{lcc}
\hline \multirow{2}{*}{ Sample } & \multicolumn{2}{c}{ Chlorine content $(\mathrm{mmol} / \mathrm{g})$} \\
& Before chlorination & After chlorination \\
\hline $\mathrm{FeCo} 450 \mathrm{Cl}$ & 0.16 & 1.53 \\
$\mathrm{Fe} 450 \mathrm{Cl}$ & 0.14 & 1.40 \\
$\mathrm{Co} 450 \mathrm{Cl}$ & 0.18 & 1.39 \\
\hline
\end{tabular}

The XPS analysis revealed the presence of chlorine species on the surface of all chlorinated samples. It was found that the amount of chlorine for the sample treated at the lowest temperature $(\mathrm{FeCo} 50 \mathrm{Cl})$ was about $1.3 \%$. Similar concentration was obtained for the sample chlorinated at $250^{\circ} \mathrm{C}$ $(\mathrm{FeCo} 250 \mathrm{Cl})$. The increase of chlorine species concentration was noticed for the sample treated at $450^{\circ} \mathrm{C}(\mathrm{FeCo} 450 \mathrm{Cl})-$ about $2.2 \%$. The quantitative analysis of the surface composition using EDS was performed as well. The samples after chlorination at $50^{\circ} \mathrm{C}, 250^{\circ} \mathrm{C}$, and $450^{\circ} \mathrm{C}$ included $0.5,1.4$, 


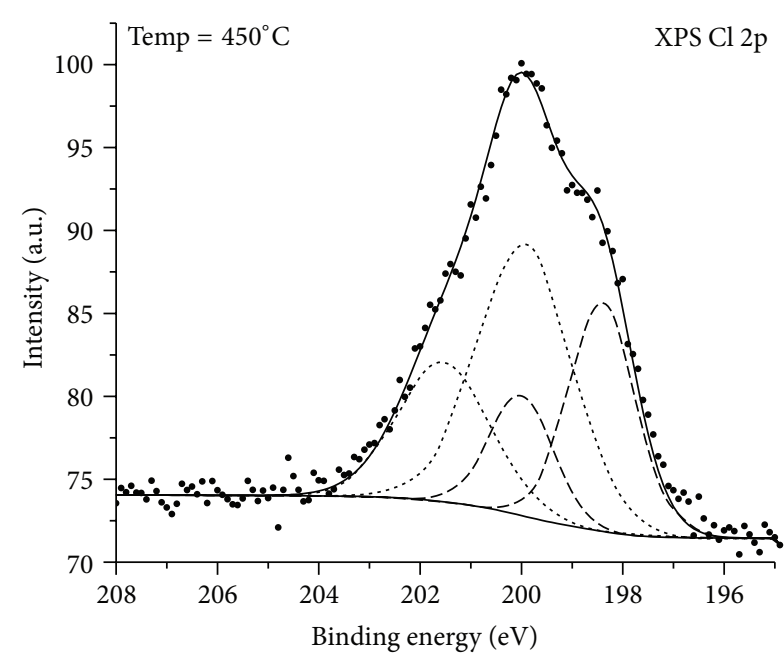

(a)

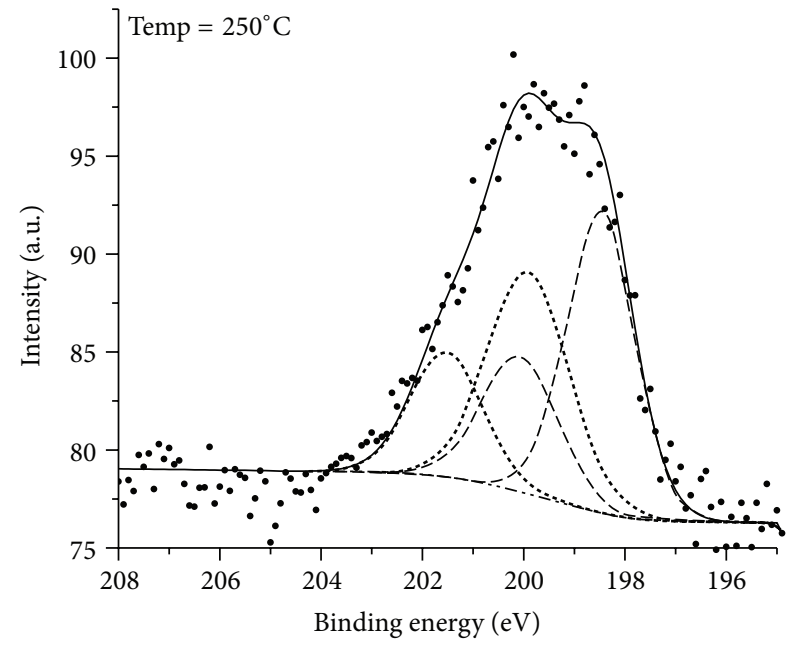

(b)

FIGURE 4: XPS Cl 2p lines for samples obtained on Fe/Co catalyst chlorinated at $250^{\circ} \mathrm{C}$ and $450^{\circ} \mathrm{C}$.

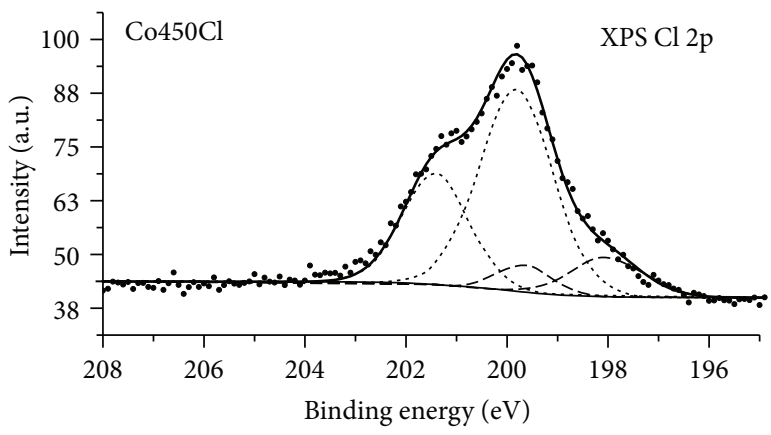

(a)

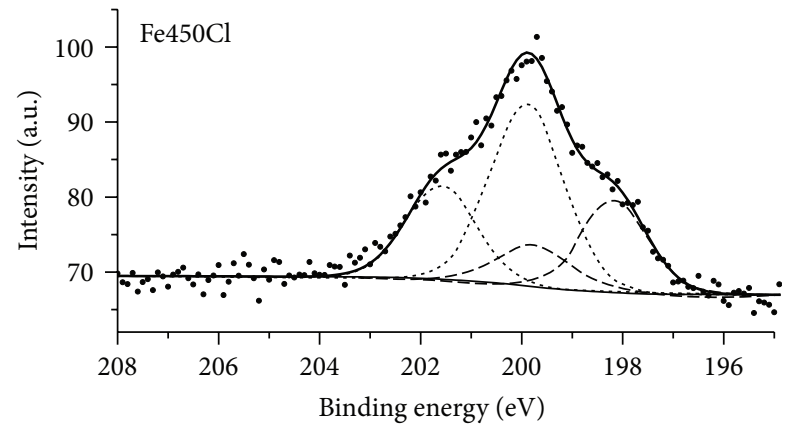

(b)

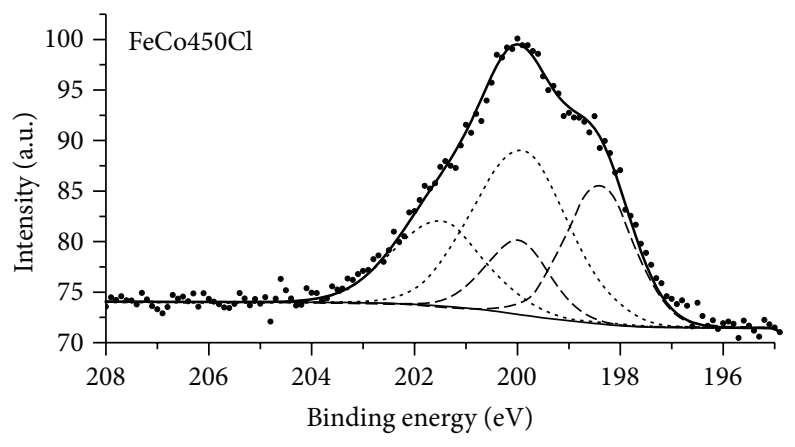

(c)

Figure 5: XPS Cl 2p lines for samples obtained on the different catalysts chlorinated at $450^{\circ} \mathrm{C}$.

and $2.3 \%$ of chlorine, respectively. Therefore together with the increase of temperature, an increasing trend in chlorine concentration on the surface was seen like in the case of the results obtained using EDS.

The XPS spectra of $\mathrm{Cl} 2 \mathrm{p}$ lines for the samples containing FeCo catalyst and treated in gas in the temperatures $250^{\circ} \mathrm{C}$ and $450^{\circ} \mathrm{C}$ are shown in Figure 4 . The other set of XPS spectra of $\mathrm{Cl} 2 \mathrm{p}$ lines compares the samples originating from three different catalysts treated at $450^{\circ} \mathrm{C}$ and are shown in Figure 5.
In case of all chlorinated samples, two components (each consisting of the $3 / 2$ and $1 / 2$ level with a spin-orbit splitting of $1.6 \mathrm{eV}$ ) are required to obtain a reasonable fit of the $\mathrm{Cl} 2 \mathrm{p}$ core level spectra. The binding energies of $3 / 2$ components are $198.5 \pm 0.1 \mathrm{eV}$ and $200.0 \pm 0.1 \mathrm{eV}$, respectively. The latter component corresponds well to chlorine atoms covalently bonded to $\mathrm{sp}^{2}$ carbon [39-41]. The low binding energy component at approximately $198.5 \mathrm{eV}$ is in the range usually ascribed to chloride ions [42]. However, there is a lack of 
metal cations in the surface of most of analyzed samples, which suggests another origin of the low binding energy component. In the literature, the position of $198.0 \mathrm{eV}$ is also ascribed to the features associated with atomic chlorine adsorbed on the surface [43].

The relative intensity of the components observed in $\mathrm{Cl} 2 \mathrm{p}$ spectra changes with temperature of the chlorination (see Figure 4). In the sample chlorinated at $250^{\circ} \mathrm{C}$, the low binding energy component at $198.5 \mathrm{eV}$ amounts to $53 \%$ of the total intensity of $\mathrm{Cl} 2 \mathrm{p}$ peak, whereas this component found in the spectrum for the sample treated at $450^{\circ} \mathrm{C}$ equals to $38 \%$ of the intensity of $\mathrm{Cl} 2 \mathrm{p}$ peak. It suggests that the chemical species corresponding to the low binding energy component decompose or desorb with a temperature rise. At higher temperature, chlorine weakly bonded with the surface presumably desorbs, but covalently bonded chlorine, represented by XPS Cl 2p line at $200 \mathrm{eV}$, remains in the material, which corresponds well with the above observations.

The comparison of XPS spectra of $\mathrm{Cl} 2 \mathrm{p}$ lines coming from samples obtained with different catalysts (Figure 5) shows that the low energy component of this spectrum has the lowest contribution in the $\mathrm{Co} 450 \mathrm{Cl}$ sample, only $16 \%$. In the sample formed on the iron catalyst, $\mathrm{Fe} 450 \mathrm{Cl}$, its contribution increases to $22 \%$, while on the surface of $\mathrm{FeCo} 450 \mathrm{Cl}$ it accounts for $38 \%$ of whole $\mathrm{Cl} 2 \mathrm{p}$ line.

Most of the available papers are concerning the introduction of chlorine species using different reagents at liquid phase. Lee et al. [29] studied functionalization of singlewalled carbon nanotubes using dichlorocarbene. It was found that chlorine atoms amounting to about 1.6 at.\%. Yuan et al. [44] involved chlorine water and ammonia water to the treatment of multi walled carbon nanotubes. On the basis of EDS spectra, it was reported that some $\mathrm{C}-\mathrm{Cl}$ bonds were introduced, but the amount of chlorine was rather low and equalled about 0.23 at.\%. Duesterg et al. [28] studied chemical functionalization of single walled carbon nanotubes using hydrothermal treatment in aqueous acidic solutions. Depending on the oxidation strength of the acids, halogen surface groups, like chlorine, were introduced on the level $<1$ at.\%. Barkauskas et al. [45] described the treatment of carbon nanotubes with tetrachloromethane, what facilitated increasing the amount of chlorine up to 6.8 at.\% in the carbon phase. Barthos et al. [27] compared functionalization of single-walled carbon nanotubes using gas chlorine and alkylhalides. Chlorine content determined by PIGE technique was in the range of 5.5-17.5 wt.\% of chlorine. Kónya et al. [30] proposed mechanochemical modification of multiwall carbon nanotubes. They stated that the use of ball milling in chemically reactive atmosphere allows us to introduce functional groups like chlorine onto carbon nanotubes, but the quantitative analysis is not presented at work. In the light of these reports, the present results show that using chlorination method in the gas phase is possible to introduce the chlorine species to the equal or even higher concentration.

\section{Conclusions}

In this work, chlorination method in the gas phase to functionalization of carbon nanotubes is proposed. Using
XPS and EDS method, the presence of chlorine species on the surface of chlorinated samples was revealed. The percentage content of chlorine species depended on chlorination temperature and equaled from about 0.5 at. $\%$ to 2.3 at.\%. Simultaneously, removal of catalyst particles was observed. On the basis of thermogravimetric curves, it was calculated that the amount of remaining catalyst particles was in the range from 0.2 to $6.5 \%$. In the light of this report, we can conclude that this method can be useful to incorporate functional groups on the carbon nanotubes surface and additionally can be applied to purification of carbon nanotubes from metal particles.

\section{Acknowledgment}

This work was supported by project: LIDER/25/58/13/11/NCBR/2012 financed by the National Centre for Research and Development.

\section{References}

[1] M. Paradise and T. Goswami, "Carbon nanotubes-production and industrial applications," Materials and Design, vol. 28, no. 5, pp. 1477-1489, 2007.

[2] V. N. Popov, "Carbon nanotubes: properties and application," Materials Science and Engineering, vol. 43, pp. 61-102, 2004.

[3] R. Oriňáková and A. Oriňák, "Recent applications of carbon nanotubes in hydrogen production and storage," Fuel, vol. 90, no. 11, pp. 3123-3140, 2011.

[4] S. C. Ray, C. W. Pao, H. M. Tsai et al., "Electronic structures and bonding properties of chlorine-treated nitrogenated carbon nanotubes: X-ray absorption and scanning photoelectron microscopy studies," Applied Physics Letters, vol. 90, no. 19, Article ID 192107, 2007.

[5] S. C. Ray, C. W. Pao, H. M. Tsai et al., "A comparative study of the electronic structures of oxygen- and chlorinetreated nitrogenated carbon nanotubes by $\mathrm{x}$-ray absorption and scanning photoelectron microscopy," Applied Physics Letters, vol. 91, no. 20, Article ID 202102, 2007.

[6] S. C. Ray, U. Palnitkar, C. W. Pao et al., "Field emission effects of nitrogenated carbon nanotubes on chlorination and oxidation," Journal of Applied Physics, vol. 104, no. 6, Article ID 063710, 2008.

[7] J. Y. Kim, S.-I. Han, and S. H. Kim, "Crystallization behaviors and mechanical properties of polyethylene 2,6-naphthalate/ multiwall carbon nanotube nanocomposites," Polymer Engineering and Science, vol. 47, no. 11, pp. 1715-1723, 2007.

[8] S. H. Jin, Y.-B. Park, and K. H. Yoon, "Rheological and mechanical properties of surface modified multi-walled carbon nanotube-filled PET composite," Composites Science and Technology, vol. 67, no. 15-16, pp. 3434-3441, 2007.

[9] B.-X. Yang, J.-H. Shi, K. P. Pramoda, and S. H. Goh, "Enhancement of stiffness, strength, ductility and toughness of poly(ethylene oxide) using phenoxy-grafted multiwalled carbon nanotubes," Nanotechnology, vol. 18, no. 12, Article ID 125606, 2007.

[10] J. Q. Pham, C. A. Mitchell, J. L. Bahr, J. M. Tour, K. Krishanamoorti, and P. F. Green, "Glass transition of polymer/ single-walled carbon nanotube composite films," Journal of Polymer Science B, vol. 41, no. 24, pp. 3339-3345, 2003. 
[11] I. V. Singh, M. Tanaka, J. Zhang, and M. Endo, "Evaluation of effective thermal conductivity of CNT-based nano-composites by element free Galerkin method," International Journal of Numerical Methods for Heat and Fluid Flow, vol. 17, no. 8, pp. 757-769, 2007.

[12] H. Guo, T. V. Sreekumar, T. Liu, M. Minus, and S. Kumar, "Structure and properties of polyacrylonitrile/single wall carbon nanotube composite films," Polymer, vol. 46, no. 9, pp. 30013005, 2005.

[13] U. Dettlaff-Weglikowska, M. Kaempgen, B. Hornbostel et al., "Conducting and transparent SWNT/polymer composites," Physica Status Solidi B, vol. 243, no. 13, pp. 3440-3444, 2006.

[14] B. R. Sankapal, K. Setyowati, J. Chen, and H. Liu, "Electrical properties of air-stable, iodine-doped carbon-nanotubepolymer composites," Applied Physics Letters, vol. 91, no. 17, Article ID 173103, 2007.

[15] V. Ivanov, A. Fonseca, J. B. Nagy et al., "Catalytic production and purification of nanotubules having fullerene-scale diameters," Carbon, vol. 33, no. 12, pp. 1727-1738, 1995.

[16] T. W. Ebbesen, P. M. Ajayan, H. Hiura, and K. Tanigaki, "Purification of nanotubes," Nature, vol. 367, no. 6463, p. 519, 1994.

[17] Y. Peng and H. Liu, "Effects of oxidation by hydrogen peroxide on the structures of multiwalled carbon nanotubes," Industrial and Engineering Chemistry Research, vol. 45, no. 19, pp. 64836488, 2006.

[18] K. Hernadi, A. Siska, L. Thiên-Nga, L. Forró, and I. Kiricsi, "Reactivity of different kinds of carbon during oxidative purification of catalytically prepared carbon nanotubes," Solid State Ionics, vol. 141-142, pp. 203-209, 2001.

[19] L. Stobinski, B. Lesiak, L. Kövér et al., "Multiwall carbon nanotubes purification and oxidation by nitric acid studied by the FTIR and electron spectroscopy methods," Journal of Alloys and Compounds, vol. 501, no. 1, pp. 77-84, 2010.

[20] S.-H. Su, W.-T. Chiang, C.-C. Lin, and M. Yokoyama, "Multiwall carbon nanotubes: purification, morphology and field emission performance," Physica E, vol. 40, no. 7, pp. 2322-2326, 2008.

[21] F. Avilés, J. V. Cauich-Rodríguez, L. Moo-Tah, A. May-Pat, and R. Vargas-Coronado, "Evaluation of mild acid oxidation treatments for MWCNT functionalization," Carbon, vol. 47, no. 13, pp. 2970-2975, 2009.

[22] P. C. Ma, J.-K. Kim, and B. Z. Tang, "Functionalization of carbon nanotubes using a silane coupling agent," Carbon, vol. 44, no. 15, pp. 3232-3238, 2006.

[23] M. A. Hamon, H. Hui, P. Bhowmik, H. M. E. Itkis, and R. C. Haddon, "Ester-functionalized soluble single-walled carbon nanotubes," Applied Physics A, vol. 74, no. 3, pp. 333-338, 2002.

[24] J. J. Stephenson, A. K. Sadana, A. L. Higginbotham, and J. M. Tour, "Highly functionalized and soluble multiwalled carbon nanotubes by reductive alkylation and arylation: the billups reaction," Chemistry of Materials, vol. 18, no. 19, pp. 4658-4661, 2006.

[25] S. Osuna, M. Torrent-Sucarrat, M. Solà, P. Geerlings, C. P. Ewels, and G. van Lier, "Reaction mechanisms for graphene and carbon nanotube fluorination," Journal of Physical Chemistry C, vol. 114, no. 8, pp. 3340-3345, 2010.

[26] L. Qu, K. M. Lee, and L. Dai, Functionalization and Applications of Carbon Nanotubes, Carbon Nanotechnology, Elsevier, edited by L. Dai, 2006.
[27] R. Barthos, D. Méhn, A. Demortier et al., "Functionalization of single-walled carbon nanotubes by using alkyl-halides," Carbon, vol. 43, no. 2, pp. 321-325, 2005.

[28] G. S. Duesberg, R. Graupner, P. Downes et al., "Hydrothermal functionalisation of single-walled carbon nanotubes," Synthetic Metals, vol. 142, no. 1-3, pp. 263-266, 2004.

[29] W. H. Lee, S. J. Kim, W. J. Lee, J. G. Lee, R. C. Haddon, and P. J. Reucroft, "X-ray photoelectron spectroscopic studies of surface modified single-walled carbon nanotube material," Applied Surface Science, vol. 181, no. 1-2, pp. 121-127, 2001.

[30] Z. Kónya, I. Vesselenyi, K. Niesz et al., "Large scale production of short functionalized carbon nanotubes," Chemical Physics Letters, vol. 360, no. 5-6, pp. 429-435, 2002.

[31] U. Narkiewicz, M. Podsiadły, R. Jȩdrzejewski, and I. Pełech, "Catalytic decomposition of hydrocarbons on cobalt, nickel and iron catalysts to obtain carbon nanomaterials," Applied Catalysis A, vol. 384, no. 1-2, pp. 27-35, 2010.

[32] I. Pełech, "Preparation of carbon nanotubes using CVD method," Polish Journal of Chemical Technology, vol. 12, pp. 4549, 2010.

[33] L. S. K. Pang, J. D. Saxby, and S. P. Chatfield, "Thermogravimetric analysis of carbon nanotubes and nanoparticles," Journal of Physical Chemistry, vol. 97, no. 27, pp. 6941-6942, 1993.

[34] Y. Hao, Z. Qunfeng, W. Fei, Q. Weizhong, and L. Guohua, "Agglomerated CNTs synthesized in a fluidized bed reactor: agglomerate structure and formation mechanism," Carbon, vol. 41, no. 14, pp. 2855-2863, 2003.

[35] Y.-Y. Fan, A. Kaufmann, A. Mukasyan, and A. Varma, "Singleand multi-wall carbon nanotubes produced using the floating catalyst method: synthesis, purification and hydrogen up-take," Carbon, vol. 44, no. 11, pp. 2160-2170, 2006.

[36] A. G. Osorio, I. C. L. Silveira, V. L. Bueno, and C. P. Bergmann, " $\mathrm{H}_{2} \mathrm{SO}_{4} / \mathrm{HNO}_{3} / \mathrm{HCl}$-functionalization and its effect on dispersion of carbon nanotubes in aqueous media," Applied Surface Science, vol. 255, no. 5, pp. 2485-2489, 2008.

[37] S. Murugesan, K. Myers, and V. R. Subramanian, "Aminofunctionalized and acid treated multi-walled carbon nanotubes as supports for electrochemical oxidation of formic acid," Applied Catalysis B, vol. 103, no. 3-4, pp. 266-274, 2011.

[38] J. Shen, W. Huang, L. Wu, Y. Hu, and M. Ye, "Study on aminofunctionalized multiwalled carbon nanotubes," Materials Science and Engineering A, vol. 464, no. 1-2, pp. 151-156, 2007.

[39] E. Papirer, R. Lacroix, J.-B. Donnet, G. Nansé, and P. Fioux, "XPS study of the halogenation of carbon black-part 2: chlorination," Carbon, vol. 33, no. 1, pp. 63-72, 1995.

[40] A. F. Pérez-Cadenas, F. J. Maldonado-Hódar, and C. MorenoCastilla, "On the nature of surface acid sites of chlorinated activated carbons," Carbon, vol. 41, no. 3, pp. 473-478, 2003.

[41] M. Vásquez, G. J. Cruz, M. G. Olayo, T. Timoshina, J. Morales, and R. Olayo, "Chlorine dopants in plasma synthesized heteroaromatic polymers," Polymer, vol. 47, no. 23, pp. 7864-7870, 2006.

[42] J. F. Moulder, W. E. Stickle, P. E. Sobol, and K. E. Bomben, Handbook of X-Ray Photoelectron Spectroscopy. Eden Prairie (Minnesota): Perkin-Elmer, 1992.

[43] H. Piao, K. Adib, and M. A. Barteau, "A temperatureprogrammed X-ray photoelectron spectroscopy (TPXPS) study of chlorine adsorption and diffusion on $\operatorname{Ag}\left(\begin{array}{lll}1 & 1 & 1\end{array}\right)$," Surface Science, vol. 557, no. 1-3, pp. 13-20, 2004. 
[44] J.-M. Yuan, X.-H. Chen, X.-H. Chen, Z.-F. Fan, X.-G. Yang, and Z.-H. Chen, "An easy method for purifying multi-walled carbon nanotubes by chlorine oxidation," Carbon, vol. 46, no. 9, pp. 1266-1269, 2008.

[45] J. Barkauskas, I. Stankevičiene, and A. Selskis, "A novel purification method of carbon nanotubes by high-temperature treatment with tetrachloromethane," Separation and Purification Technology, vol. 71, no. 3, pp. 331-336, 2010. 

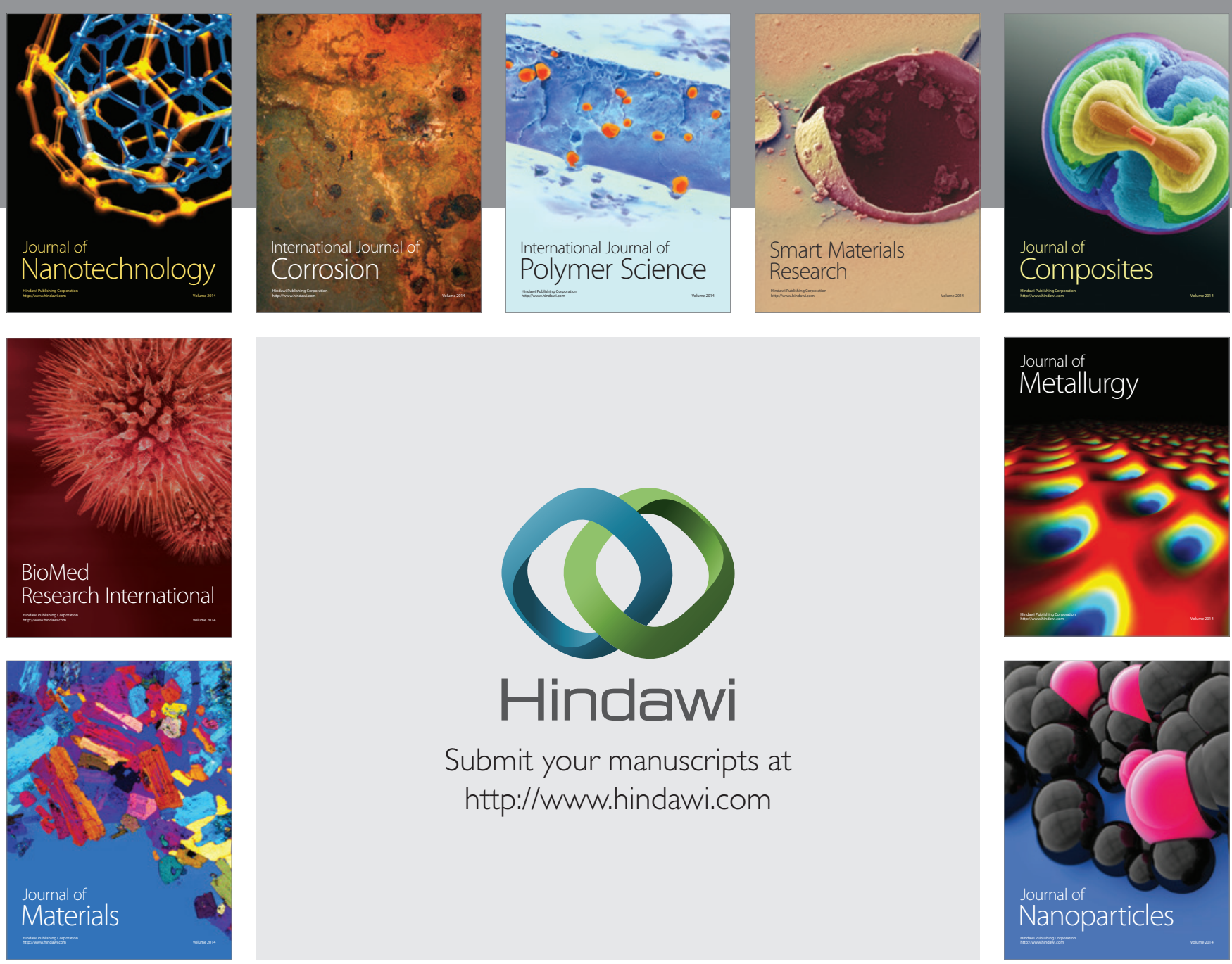

Submit your manuscripts at http://www.hindawi.com
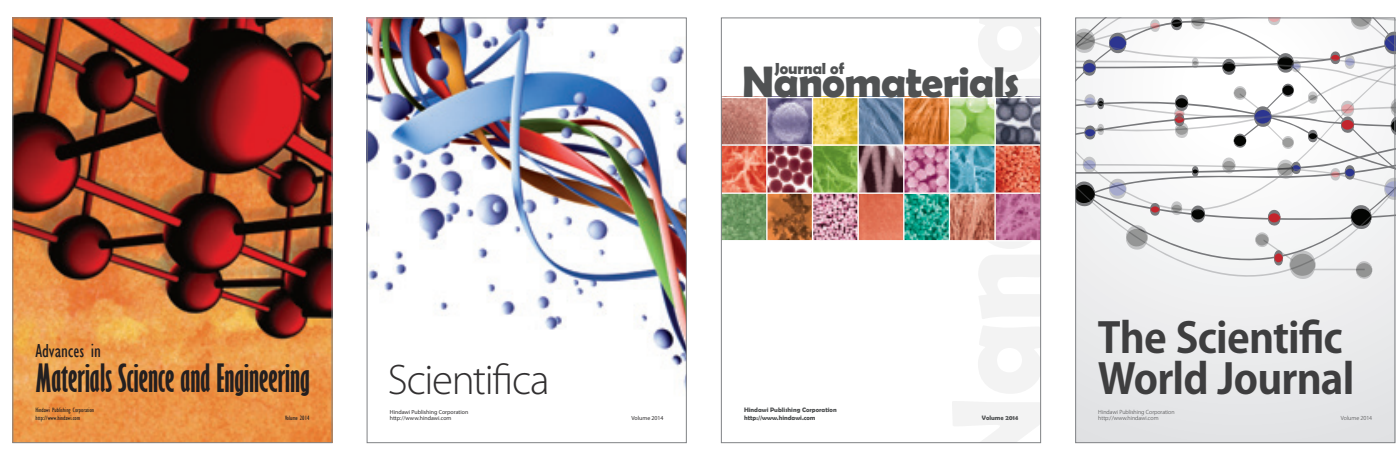

\section{The Scientific World Journal}
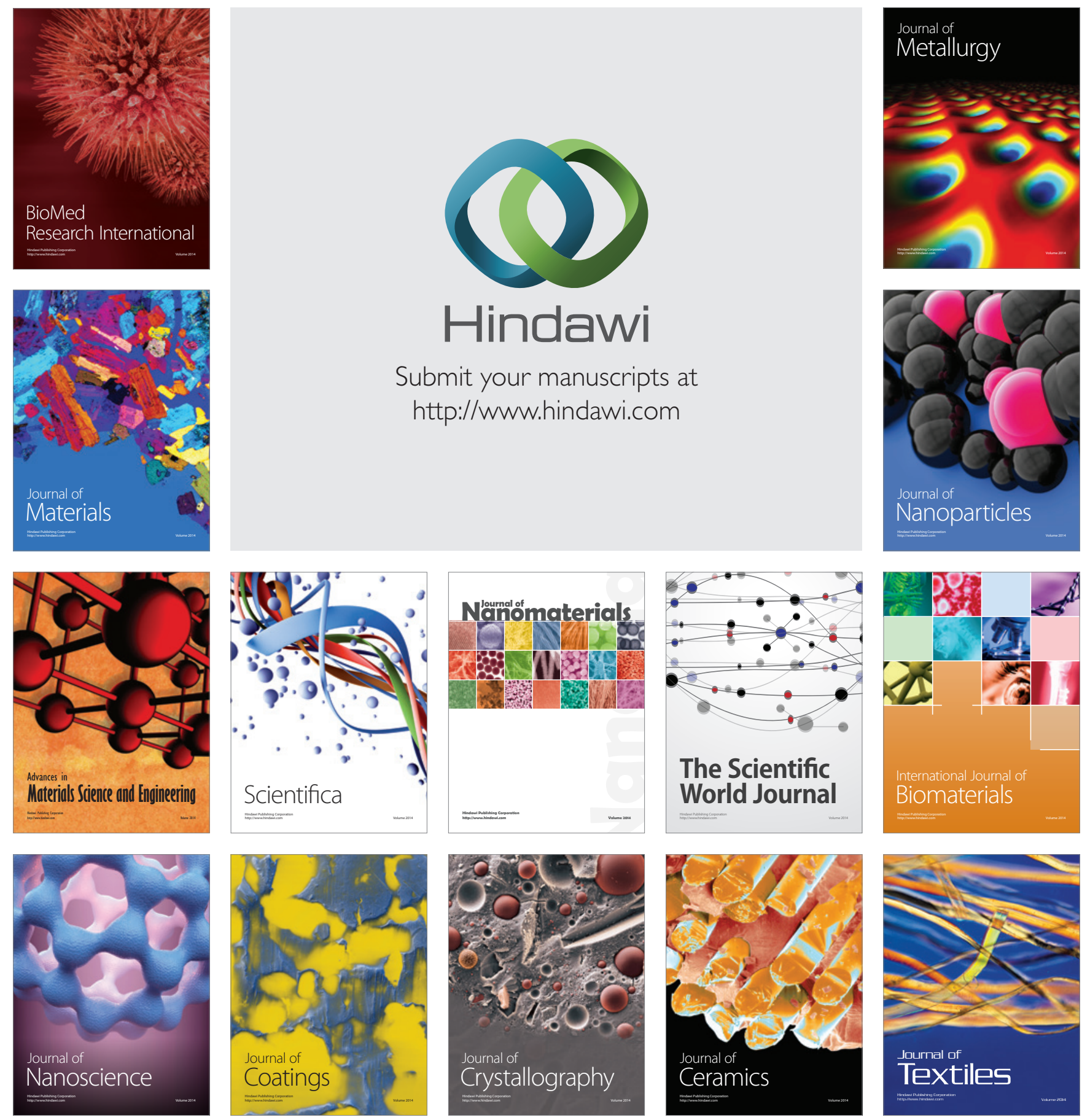